\title{
The Role of School Feeding Program Supported by DAL Company in Students' Enrolment and Drop-out
}

\author{
Dr. Hind Bushra Ahmed Ibrahim \\ School of Rural Extension Education and Development (REED) \\ Ahfad University for Women, Po. Box 167.0mdurman, Sudan
}

\begin{abstract}
School feeding program as a social safety net has been popular in developing countries as an instrument for achieving the Millennium Development Goals. These programs are frequently targeted towards families' low socioeconomic status and unable to send their children to school or face poor attendance and drop-out from school .In the present study an attempt has been made to analyse the role of school feeding program supported by DAL Company in students' enrollment and Drop-out in Ombadda Locality ( Alamal and Ahmad AlrdeeGaber school). The results showed that majority of the students' parents were suffering formal education, worked in the informal sector to support their families. All teachers and students' parents considered the most frequent reasons for dropping out of or not enrolling in school are the poor financial standing of the family. Also, all of them agreed upon DAL school feeding program have positively impact on educational attainment by increasing enrolment, attendance and reduced students' drop-out.
\end{abstract}

Key words: school drop-out, school feeding

\section{INTRODUCTION}

According to the 2007, Food and Agriculture Organization's (FAO) estimate, 923 million people in the world were chronically hungry, which was an increase of about 75 million people from the 2003-05 estimates (FAO 2008). Many of these are children, and a vast majority of them are in developing countries. These numbers suggest that the Millennium Development Goals related to hunger and malnutrition may not be met by 2015. The persistence of hunger, malnutrition, and micronutrient deficiencies can have long lasting effects on the health status and productivity of people and their nations.

In response to these challenges, various interventions have been undertaken by Policy makers to target various groups within a population through social safety nets to address the problem of hunger and malnutrition. One intervention that governments and non-governmental organizations (NGO) have utilized in targeted areas where a significant part of the population faces poverty and chronic hunger is Food for Education (FFE). FFE provides food to school children or their family in exchange for enrollment and attendance in school, and directly relates to the first three Millennium Development Goals: to eradicate extreme poverty and hunger, achieve universal basiceducation, and promote gender equality and empower women by 2015.(WFP 2009).

School feeding was assumed as a measure to address the problem of students' enrolment and dropout in some hunger prone regions in the country. The available empirical studies shows that, school feeding has positively contributed to students enrolment and reduced students' dropout in basicschools in many developing countries (Jomaa et al., 2011). A drop-out can be 
defined as a child who enrols in school but fails to complete the relevant level of the educational cycle. At the basiclevel this means that the drop-out fails to reach the final grade,

School feeding programs can thus be a powerful instrument for achieving many multi-sectoral benefits - education, gender equality, food security, poverty reduction, nutrition and health, and agricultural development. The recent food, fuel and financial crises have highlighted the importance of school feeding programs both as a social safety net for children living in poverty and food insecurity, and as a tool for stimulating local agricultural production and economic opportunities in rural communities.

In May 2011, DAL Group and DAL Dairy Factory introduced the pilot school milk programme in the remote areas of Khartoum to alleviate malnutrition, improve health and school attendance levels, as well as habituate milk consumption among school children. When the pilot programme started, it covered seven schools considered most in need, but the programme has grown to cover 16,000 children in 30 schools. The children get milk once a day, five days a week. Many of these children live without the basics of life and the milk could be one of few or the only - meals during one day. (http://www.tetrapak.com/rs/sustainability/cases-andarticles, 2014)

The main aim of this paper is highlights the role of DAL company's school feeding programme on school enrolment, class attendance and student drop-out among basicschool children, in Alamal and Ahmad AlrdeeGaber basicschools in Ombdda Locality.

\section{METHODOLOGY}

The study was conducted in Khartoum State (Ombadda locality),the qualitative method was used, in depth interview with school teachers and focus group discussion with students; parents , A sample of 20 parents of students who dropped out total of four groups discussion , each school had two groups discussion , and 7 teachers from Ahmed AlradiGaber and Alamel School in Omdurman - Ombada Locality were purposively selected. . The following points were discussed with parents are:

- Perception of students' parents towards importance of education.

- Factors behind students dropout

- Effect of school feeding programm supported by DAL Company on the student's dropout.

Content analysis was used to analyze data collected from target groups.

\section{Characteristics of the Schools}

\section{RESULTS AND DISCUSSION:}

The sample schools selected for the study in the area have almost the same characteristics. Most schools observed lack basic school and educational facilities like bad fence, tap water, toilet, playground, text books, stationary materials and furniture. All schools in the study area do not have electric power supply.

\section{Socio-economic characteristics of the students' parents}

All students' parents participated on in-depth interview were currently married. Ages of them range between 20 to 50 years old. Each of them had between 5 to 8children and the majority of them are young. Most of them were suffering formal education, worked in the informal sector 
to support their families. Most of them have been displaced to this area more than ten years ago due to different reasons (War, draught and desertification).

\section{Students' parents perception toward education and its importance}

Most of parents have considered of the importance of the education of their children's and willing sending their children's to schools including their daughters. Also all of them approved by the benefits of the education and make a better opportunity for theirlife.

\section{Factors affect children's enrolment and attendance in the area}

Information of this part had been taken from in-depth interview with head teachers and five teachers of the Ahmed AlradiGaber and Alamel BasicSchools.

\begin{tabular}{|c|c|c|}
\hline No & Respondent & Answer \\
\hline \multirow[t]{6}{*}{2} & 1 & $\begin{array}{l}\text { Very poor families, the absence of the father in most families, the } \\
\text { absence of the father in most families , and the lack of a person } \\
\text { responsible for the care of the academic of the students }\end{array}$ \\
\hline & 2,3 & Very poor families and the absence of the father in most families \\
\hline & 4 & $\begin{array}{l}\text { Very poor families, the absence of the father in most families and } \\
\text { stumbled student in the study leads to a lack of student's desire to } \\
\text { continue to study }\end{array}$ \\
\hline & 5 & $\begin{array}{l}\text { Very poor families, the absence of the father in most families and } \\
\text { students work to increase the family income }\end{array}$ \\
\hline & 6 & $\begin{array}{l}\text { Very poor families, the absence of the father in most families and the } \\
\text { low educational level of parents }\end{array}$ \\
\hline & 7 & $\begin{array}{l}\text { The lack of the parents interest in education and the lack of a person } \\
\text { responsible for the care of the academic of the students }\end{array}$ \\
\hline
\end{tabular}

Generally the result of the school teachers was agreed with the students' parents group discussion results, all parents considered the most frequent reasons for dropping out of or not enrolling in school are the poor financial standing of the family, lack of parental support and the distance from the school. In addition, the following reasons have been reported, low academic performance, demotic responsibilities and school environment.

From the result above, it is clear that the number of children enrolled in school has increased over time. Nevertheless, a significant proportion of children who start basicschool are notcompleting this cycle. There are many factors associated with drop out,some of which belong to the individual, such as poor health or malnutrition and motivation. Others emerge from children's household situations such as child labour and poverty. School level factors also play a role in increasing pressures to drop out such as teacher's absenteeism, school location and poor quality educational provision. In addition, the lack of awareness and information amongst some parents concerning the importance of education, this is particularly common amongst parents with low levelsof education and intellectually disabled parents.

These results agreed with (Hunt, 2008), he said that, there is not one single cause of drop out. Drop out is often a process rather than theresult of one single event, and therefore has more than one proximate cause. 
Also regarding (Colclough, et al.2000).

"Povertyappears to influence the demand for schooling, not only because it affects the inability of households to pay school fees and other costs associated with education, but also because it is associated with a high opportunity cost of schooling for children. As children grow older, the opportunity cost of education is even larger, hence increasing the pressure for children to work and earn income for the household as opposed to spending time in education. Distance to schools, poor quality of education, inadequate facilities, overcrowded classrooms, inappropriate language of instruction, teacher absenteeism and, in the case of girls school safety, are common causes for school dropout. Additional factors affecting motivations and decision-making relating to educational access are also key to understandings of dropping out. Perceptions of how education will influence life style and career possibilities/probabilities, life chances in the labour market are shown to be factors in both early withdrawal and sustained access in different contexts".

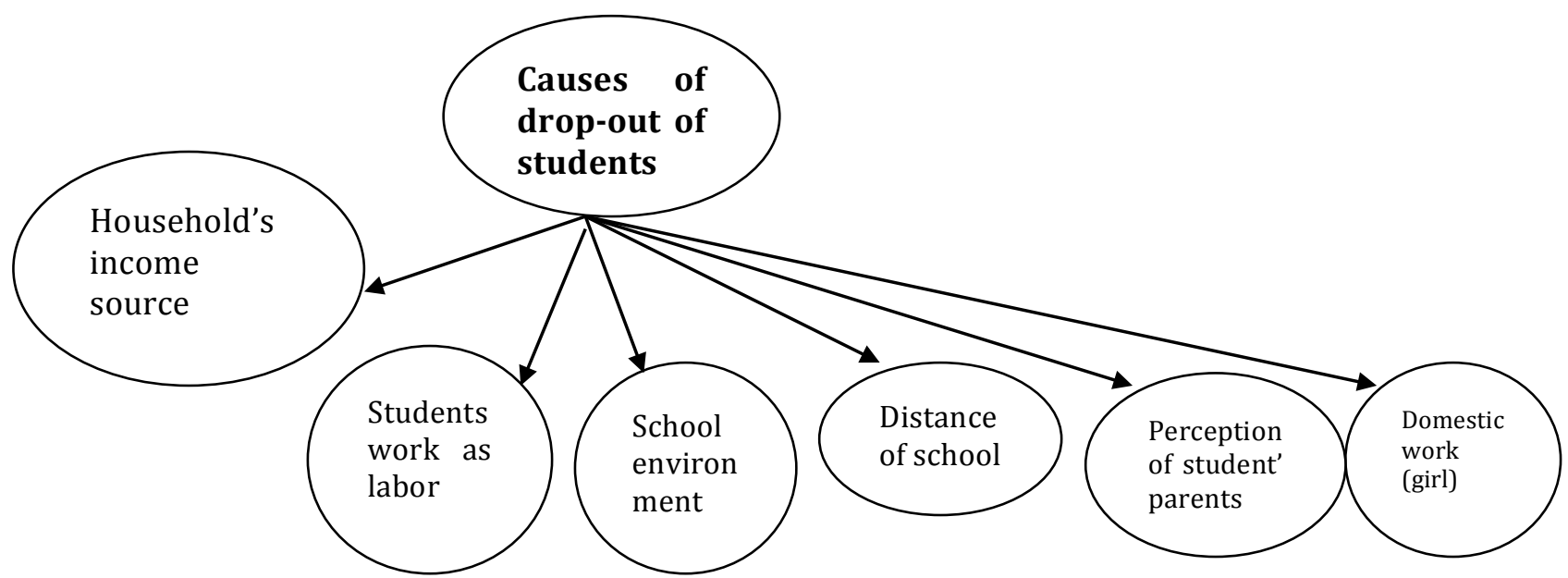

Knowledge and Perception of the parents, students and teachers on the contribution of DAL's school feeding program in the increase of students' enrollment and decrease student's dropout from basicschools.

Most of the students' parents are known about the school feeding program, this through orientation session presented by member of DAL company inside the two schools, in this orientation session, people were show and identify which form of Food for Education Programs was supported to their children. All students' parents agreed that, DAL Company provided meals or snacks to school children on the site (Milk, Yogurt). This agreedwith (Adelman et al. 2008).

Food for education programs (FFE), including meals served in school and take home rations conditional on school attendance, have recently received renewed attention as a policy instrument for achieving the Millennium Development Goals of universal basiceducation and the reduction of hunger in developing countries."

from results above, the benefit of the food provided under the school feeding programs is conditional on the attendance of the child on that specific day. Thus an advantage of the SFP is that it serves as an encouragement for children to attend school on a daily basis to receive a meal, whereas to receive the benefit of take-home rations (THR), students need only to attend a specified minimum number of days. 
Generally, the objectives for the school meals are mainly three; school feeding as a social safety Net, as a need to improve learning and educational outcomes, and to enhance nutrition and or health status of the schoolchildren. This agreed with. (WFP (2009)

"Objectives behind all Food for Education (FFE) programs are primarily educational; that is, the program aims to improve educational outcomes through improved access and participation in education, particularly through increased enrollment and reduce dropout. These objectives may include the alleviation of short-term hunger, which enable students to concentrate and learn better."

Regarding to role of the school feeding program, the majority of the parents were very admitted by the benefits of the program and mentioned; first, school meals will increased school enrollment and increased class attendance. It is students' parents believed that school meals can be effective at increasing class attendance because children received the meal only when they attend school. Because school meals improved class attendance, children will spend more time learning in school. So the more time children spend in school, the better they learn and these relationships ultimately result in improved school performance.

From the results above, there are two main indicators of the impact of school feeding, first school enrolment, and second is class attendance, class attendance can be measured by absence rate. These two indicators can be used to determine if the School Feeding Program has significant positive impact on school participation.

"School feeding programs positively impact educational attainment by increasing enrolment and attendance, reducing absenteeism due to illness and decreasing dropout. In many countries, school feeding programs are one of the key incentives to encourage children, especially girls and the poorest and most vulnerable children to attend school" (Powell et al. 2006).

Regarding http://www.tetrapak.com/rs/sustainability/cases-and-articlesI, In many schools attendance has increased from 50\% to nearly $100 \%$ after implementing the DAL 'sschool milk programme. Teachers can verify that the children are energised and have better capabilities to learn. Furthermore, the University of Medical Sciences and Technology in Khartoum has been following the school milk programme with a health assessment study.Among many positive results, the study shows that the number of children being underweight has been reduced by $50 \%$ after introducing the school milk programme. 
figure No (1) Relationship between SFP and potential outcomes and impacts on school children

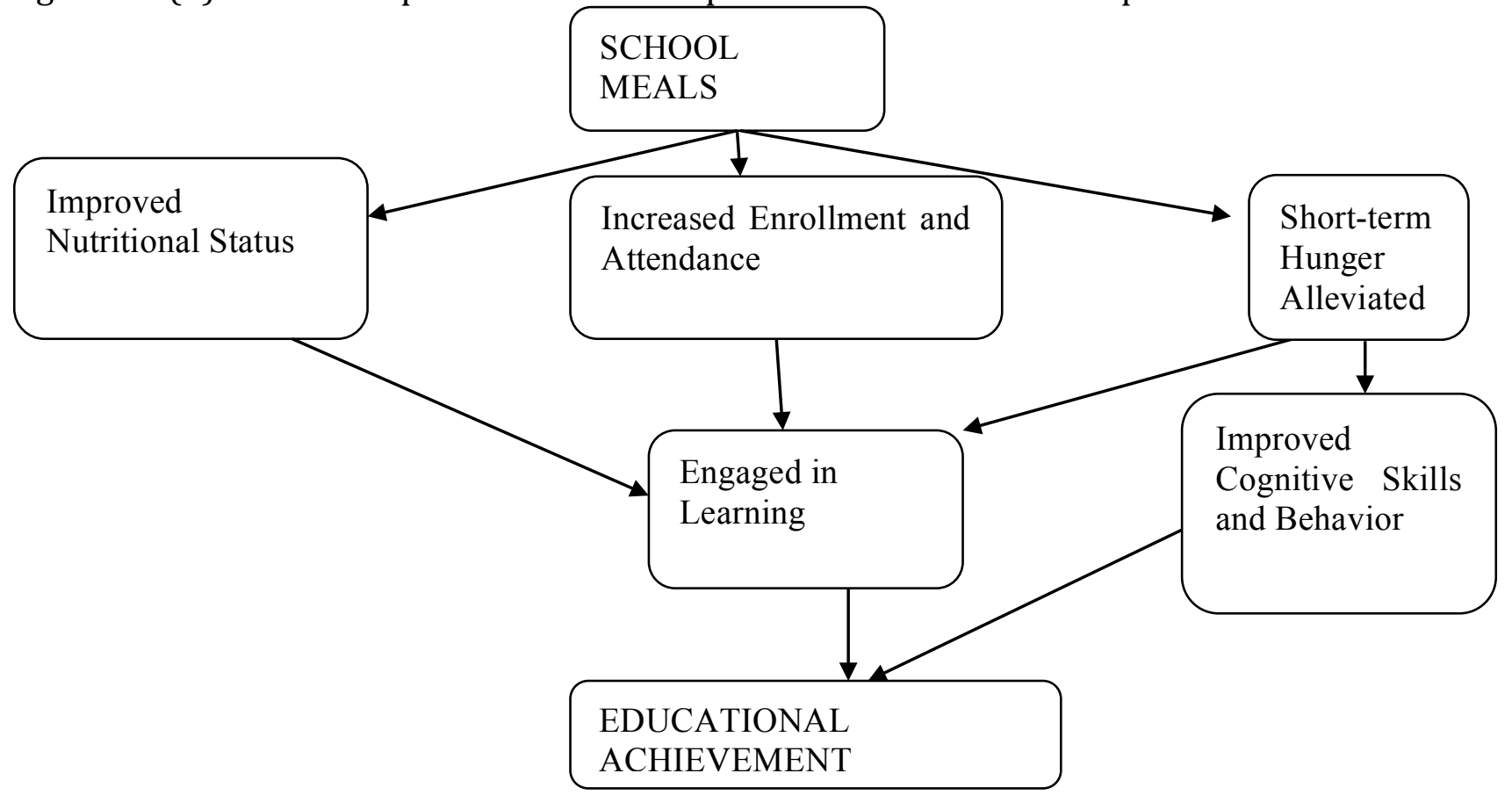

Source: Adapted from Grantham-McGregor et al. (1998) and Jacoby et al. (1998).

\section{CONCLUSION}

In this study, attempts have been made to identify factors affecting school participation in the study area. Accordingly, the major factors affecting enrollment are the poor financial standing of the family, demand for child labor, cost of schooling, availability of school, teaching quality and school infrastructure, distance to school, the availability of food incentives and safety concerns. Also, attempts have been made to evaluate the significance of School Feeding Program in enhancing school participation among basic school children in Ahmed AlradiGaber and Alamel School in Omdurman - Ombada Locality. The result shows that, School Feeding Program has positive roles on school participation and significant effects. The results of the study found significant increase in enrollment as a result of school meals. It is observed that the existing program presents more incentive to attract children to school or enable parents send children to school and increase in attendance.

This could primarily be due to the adequacy (to some extent, milk) of school meals to augment the nutritional status of children as observed during the study. School Feeding Program also shows significant positive impacts on drop-out rates also (to some extent) because there have another factors cause's school drop-out.

Finally the study recommended that,

- Local authorities can build and strengthen partnership with private sector (Corporate Social Responsibility).

- Authorities should support education by making basic schooling free.

\section{References}

- $\quad$ Adelman, S. W., D. O. Gilligan, and K. Lehrer (2008) “How Effective are Food for Education Programs?” International Food Policy Research Institute 
- Colclough, C., Rose, P. and Tembon, M. (2000). 'Gender Inequalities in BasicSchooling: Development, 20: 5-27.

- Food and Agriculture Organization of the United Nations, The State of Food Insecurity in the World. Rome: FAO, 2008.

- Grantham-McGregor, S. M., Chang, S., Walker, S. P., Evaluation of School Feeding Programs: Some Jamaican Examples. The American Journal of Clinical Nutrition, 1998; 67:785S-9S.

- Hunt, F. (2008). 'Dropping out from school: A cross-country review of literature.' CREATEPathways to Access No 16. Consortium for Research on Educational Access, Transitions andEquity: University of Sussex.

- http://www.tetrapak.com/rs/sustainability/cases-and-articles, 2014, School Milk in Sudan,

- Jomaa, L. H., McDonnell, E., \&Probart, C. (2011). School feeding programs in developing countries: impacts on children's health and educational outcomes. Nutrition Reviews.

- $\quad$ Powell, C. A., Walker, S. P., Chang, S. M., \& Grantham-McGregor, S. M. (1998). Nutrition and education: a randomized trial of the effects of breakfast in rural basicschool children.American Journal of Clinical Nutrition, 68, 4, 873-879. The Roles of Poverty and Adverse Cultural Practice.' International Journal of Educational.

- UNESCO, (2012) Youth and skills: Putting education to work, EFA global monitoring report, 2012; retrieved 1/11/2013, 2013, from http://unesdoc.unesco.org/ulis/cgi bin/ulis.pl?catno=218003\&gp=1\&mode=e\&lin=1

- WFP (2009). CHILD Based Food for Education. W. F. Programme. Addis Ababa. 